\title{
Intermittent obstruction resulting from multiple intestinal webs
}

Kristel Lobo Prabhu BSc ${ }^{1}$, Robert Enns MD FRCPC ${ }^{2,3}$, Carl J Brown MD MSc FRCSC ${ }^{1,3}$

K Lobo Prabhu, R Enns, CJ Brown. Intermittent obstruction resulting from multiple intestinal webs. Can J Gastroenterol 2010;24(2):101-102.

Intestinal webs are a rare cause of bowel obstruction. A case of a 32-year-old man with multiple intestinal webs causing intermittent, partial bowel obstruction is described. The webs were initially detected with capsule endoscopy. The patient was treated with intraoperative endoscopy and balloon dilation. At early follow-up, no recurrence of his symptoms was evident.

Key Words: Balloon dilation; Intestinal webs; Small bowel obstruction

\section{Une occlusion intermittente causée par des brides intestinales multiples}

Les brides intestinales sont une rare cause d'occlusion intestinale. Les auteurs décrivent le cas d'un homme de 32 ans ayant de multiples brides intestinales provoquant une occlusion intestinale partielle et intermittente. On les a d'abord décelées par endoscopie capsulaire. On a traité le patient au moyen d'une endoscopie intra-opératoire et d'une dilatation par ballonnet. Au suivi précoce, on n’a observé aucune récurrence de ses symptômes.

\section{CASE PRESENTATION}

A 32-year-old man presented with a seven-year history of abdominal pain exacerbated by high-fibre foods such as fruits and vegetables. Several hours after ingestion, the patient would experience sharp, cramping, epigastric pain and bloating that would last several hours. He would restrict himself to a clear fluid diet, which resolved the obstructive symptoms. Over the years, he managed to minimize his symptoms by remaining on a low-fibre diet. He produced two well-formed bowel movements per day throughout this time. While he experienced some weight loss early in his clinical course, his weight had been stable at $77.1 \mathrm{~kg}$ over the past two years while on his modified diet. His medical history was significant for a cholecystectomy. He denied lifetime nonsteroidal anti-inflammatory drug (NSAID) use. His physical examination was normal.

The patient underwent a small bowel follow-through study that showed no evidence of focal stricturing. An abdominal computed tomography scan showed prominent fluid-filled loops of small bowel, but no evidence of obstruction. Upper endoscopy demonstrated no abnormality. Terminal ileal biopsies taken during a routine colonoscopy showed mild ileal inflammation that was not characteristic of Crohn's disease. An enteroscopy to the jejunum showed no abnormality. A small bowel capsule study revealed a pinpoint opening in the bowel beyond which the capsule did not advance - despite being in the gastrointestinal tract for several hours (Figure 1).

The patient agreed to laparotomy to treat the stricture and remove the capsule. On surgical visualization, multiple areas of dilated small bowel loops extending from the jejunum to the distal ileum were seen. An enterotomy at the location of the capsule revealed an obvious web that was excised surgically with cautery and closed using the Heineke-Mikulicz strictureplasty technique. This web would not have been identified without the presence of the stalled capsule. Evaluation of the small bowel revealed multiple areas that were suspicious for webs. At laparotomy, multiple webs were not expected and,

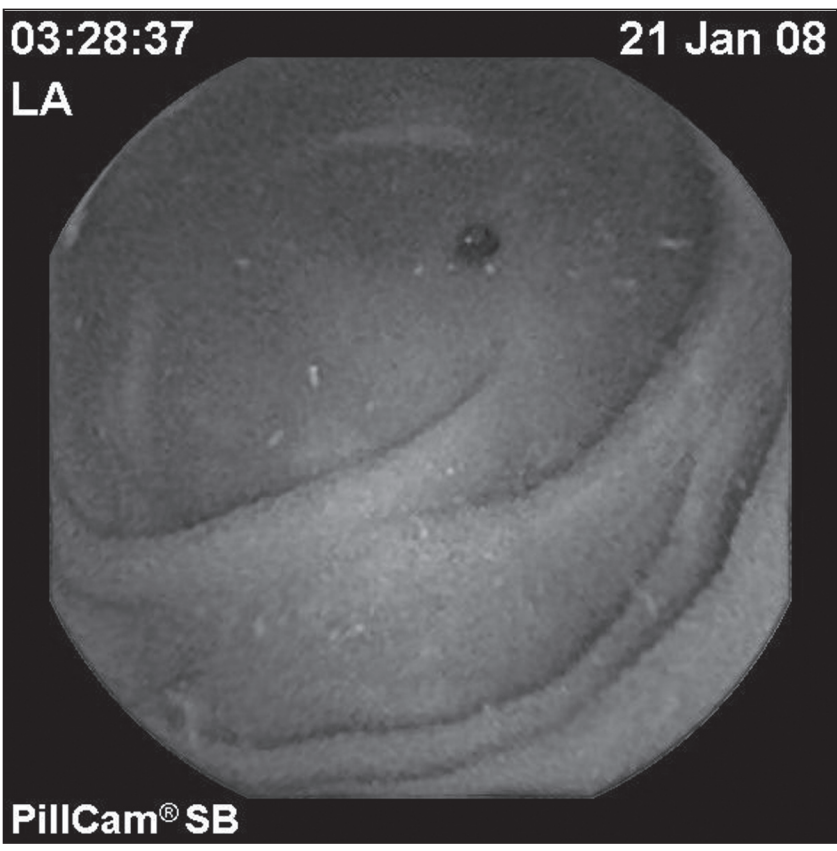

Figure 1) Capsule endoscopy image showing a pinpoint opening in the bowel representing the web. Pillcam SB, Given Imaging Ltd, USA

thus, a decision was made to close the abdomen and pursue endoscopic therapy.

Biopsies of the web confirmed normal mucosa, with no evidence of inflammation or malignancy. Attempts to dilate the webs with single- and double-balloon enteroscopy, performed several weeks later, were unsuccessful.

Finally, repeat laparotomy with intraoperative endoscopy was performed. A pediatric colonoscope was passed through a mid small bowel enterotomy. Five distal webs and one proximal web were balloon dilated with a controlled radial expansion, wire-guided, $18 \mathrm{~mm}$ to $20 \mathrm{~mm}$ esophageal/pyloric/colonic

${ }^{1}$ Department of Surgery; ${ }^{2}$ Department of Medicine, University of British Columbia; ${ }^{3}$ St Paul's Hospital, Vancouver, British Columbia

Correspondence: Dr Carl J Brown, Room 310, St Paul's Hospital, 1081 Burrard Street, Vancouver, British Columbia V6Z 1 Y6.

Telephone 604-806-8711,fax 604-806-9604, e-mail cbrown@providencehealth.bc.ca

Received for publication June 2, 2009. Accepted June 3, 2009 

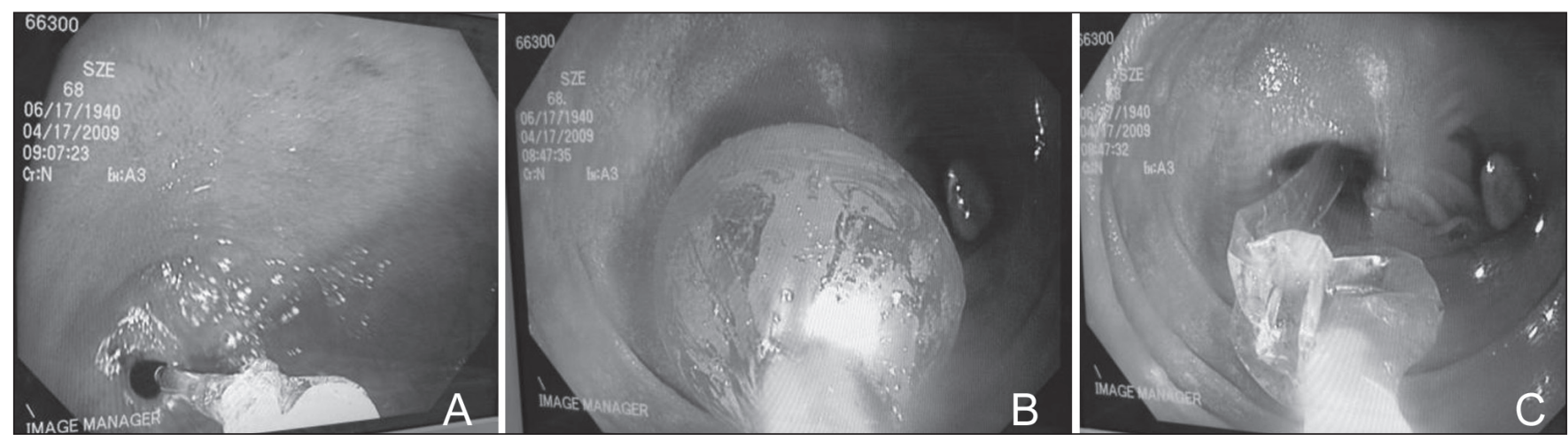

Figure 2) Endoscopic images of a small bowel web before (A), during (B) and after balloon dilation (C)

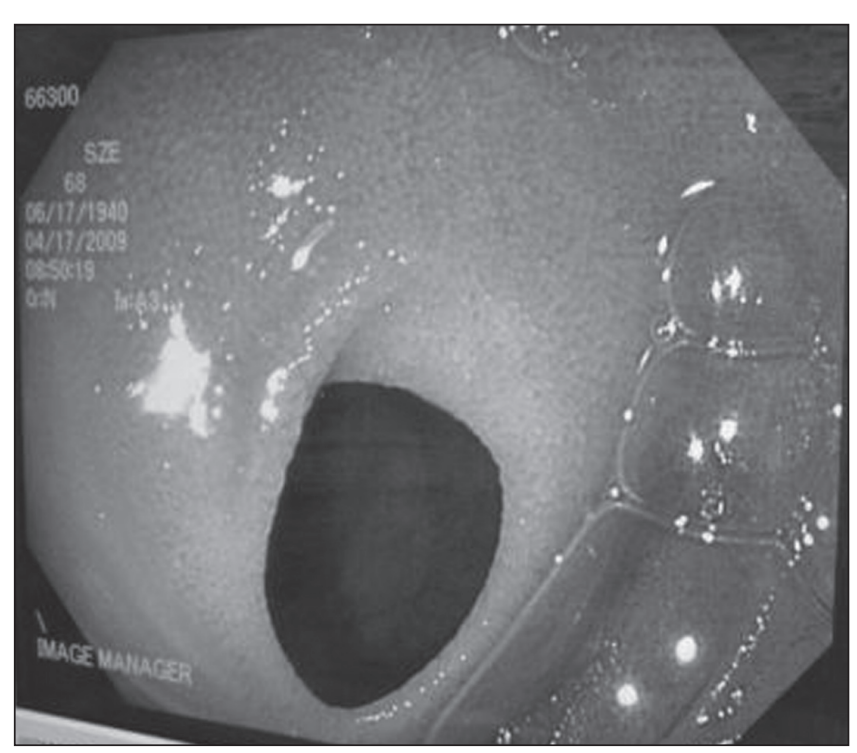

Figure 3) Endoscopic image of a partial, nonobstructing small bowel web that was not balloon dilated

balloon dilation catheter (Figure 2). Endoscopically, there were at least 20 webs through which the colonoscope could pass and were left undisturbed (Figure 3). The entire small bowel was evaluated during the procedure.

Following the procedure, the patient was started on a diet of clear fluids and then advanced to a regular diet that was well tolerated. At six months follow-up, there were no further episodes of obstruction.

\section{DISCUSSION}

Mechanical small bowel obstruction may be caused by lesions intrinsic to the intestinal wall. These lesions may be the result of congenital, inflammatory, neoplastic or traumatic etiologies. Adenocarcinoma, Crohn's disease, intramural hemorrhage and intussusception are common causes of intrinsic intestinal obstruction and must be considered in the differential examination (1). Intestinal webs are a rare cause of bowel obstruction.

NSAID use is associated with the development of diaphragmor web-like strictures in the small bowel (2). NSAIDs alter enterocyte permeability and inhibit the production of protective prostaglandins, thus leading to mucosal ulceration in the small bowel (2). Diaphragm formation is hypothesized to be the result of pathological progression of circumferential ulceration caused by NSAID use (3). The patient described in the present report denied NSAID use.
Congenital webs causing intestinal obstruction are encountered in the pediatric population. Jejunoileal obstruction is the result of intrauterine ischemic injury and may occur anywhere between the ligament of Treitz and the ileocecal valve (4). Twenty per cent of these atresias are a result of intraluminal diaphragms or webs that narrow the lumen but maintain communication between the proximal and distal segments of bowel (5). Reports of congenital intestinal webs in adults are exceedingly rare (6). A congenital etiology may be considered in our patient given the duration of his symptoms and the normal mucosa seen on pathology. There is one other case reported in the literature with similar presentation of which we are aware (7). Webs have become more apparent with the advent of capsule endoscopy $(8,9)$. Webs are often missed on barium studies because they are thin, with barium pooling on either side, obscuring the defect. Capsule endoscopy typically reveals the web. While the capsule does not usually cause obstruction at the web site, it can remain stalled there.

The unusual, longstanding duration of symptoms at presentation and uncertain etiology of intestinal webs in our patient made the present case interesting. Webs must be considered in the differential diagnosis of chronic, intermittent, small bowel obstruction, particularly in patients with a history of NSAID use.

\section{REFERENCES}

1. Boudiaf M, Soyer P, Terem C, Pelage JP, Maissiat E, Rymer R. $\mathrm{CT}$ evaluation of small bowel obstruction. Radiographics 2001;21:613-24.

2. Zalev AH, Gardiner GW, Warren RE. NSAID injury to the small intestine. Abdom Imaging 1998;23:40-4.

3. Going JJ, Canvin J, Sturrock R. Possible precursor of diaphragm disease in the small intestine. Lancet 1993;341:638-9. (Lett)

4. Koffeman GI, van Gemert WG, George EK, Veenendaal RA. Classification, epidemiology and aetiology. Best Pract Res Clin Gastroenterol 2003;17:879-93.

5. Grosfeld JL. Jejunoilal atresia and stenosis. In: O’Neill JA, Rowe MI, Grosfeld JL, eds. Pediatric Surgery, 5th edn. St Louis: CV Mosby, 1998:1145-58.

6. Santolaria S, Cabezali R, Ortego J, Castiella T, Salinas JC, Lanas A. Diaphragm disease of the small bowel: A case without apparent nonsteroidal anti-inflammatory drug use. J Clin Gastroenterol 2001;32:344-6.

7. Van Buren G II,Teichgraeber DC, Ghorbani RP, Souchon EA. Sequential stenotic strictures of the small bowel leading to obstruction. World J Gastroenterol 2007;13:5391-3.

8. Yousfi MM, De Petris G, Leighton JA, et al. Diaphragm disease after use of nonsteroidal anti-inflammatory agents: First report of diagnosis with capsule endoscopy. J Clin Gastroenterol 2004;38:686-91.

9. Hatoum OA, Binion DG, Phillips SA, et al. Radiation-induced small bowel "web" formation is associated with acquired microvascular dysfunction. Gut 2005;54:1797-800. 


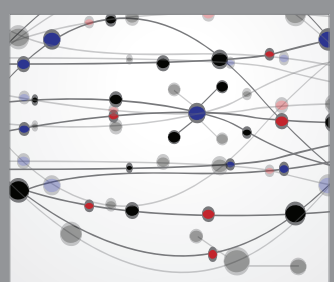

The Scientific World Journal
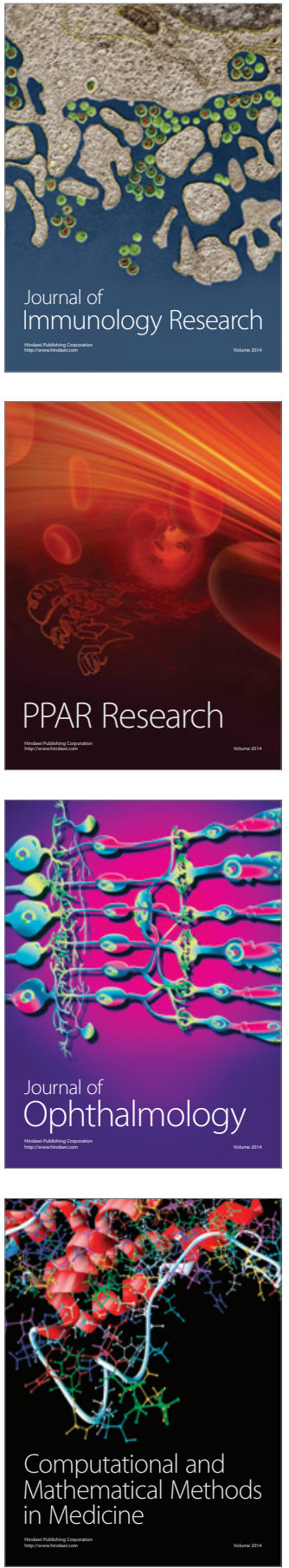

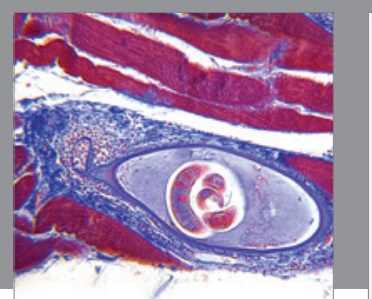

Gastroenterology Research and Practice

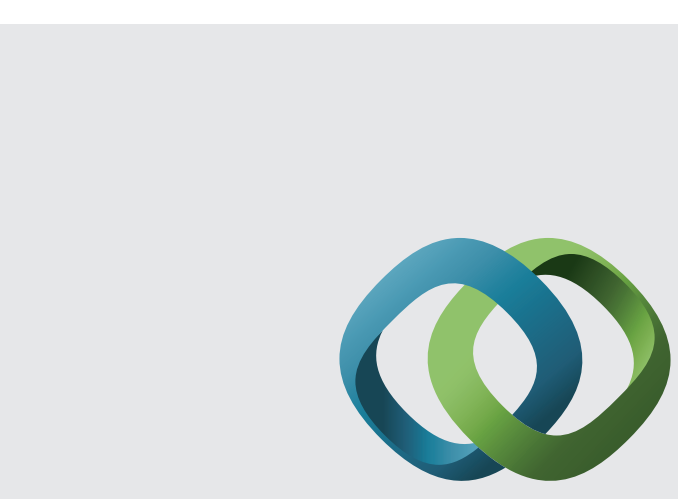

\section{Hindawi}

Submit your manuscripts at

http://www.hindawi.com
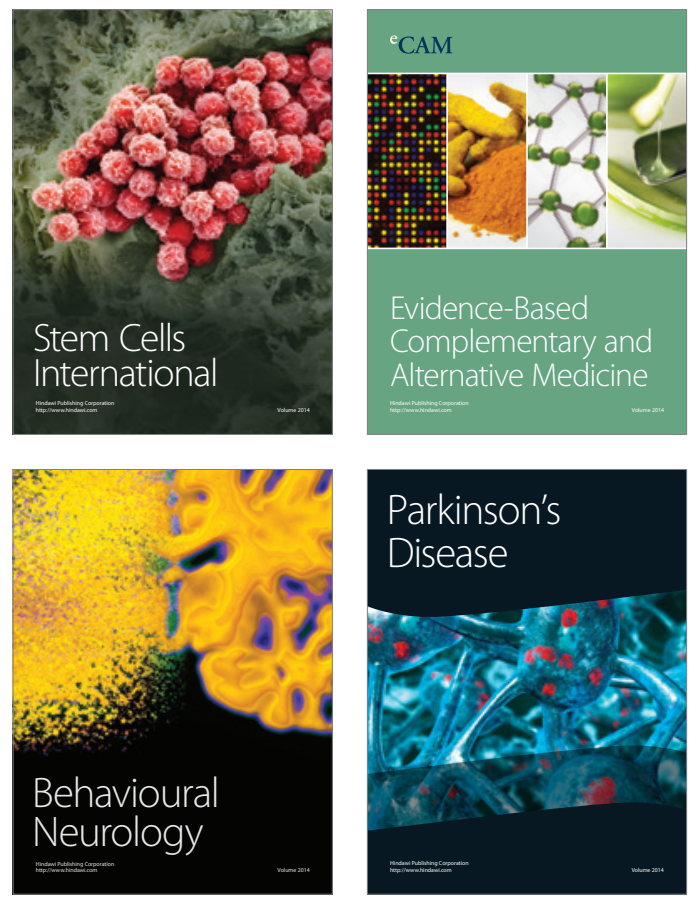
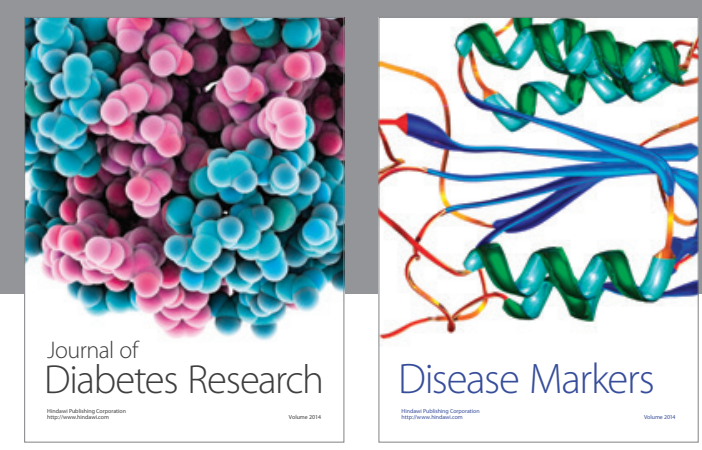

Disease Markers
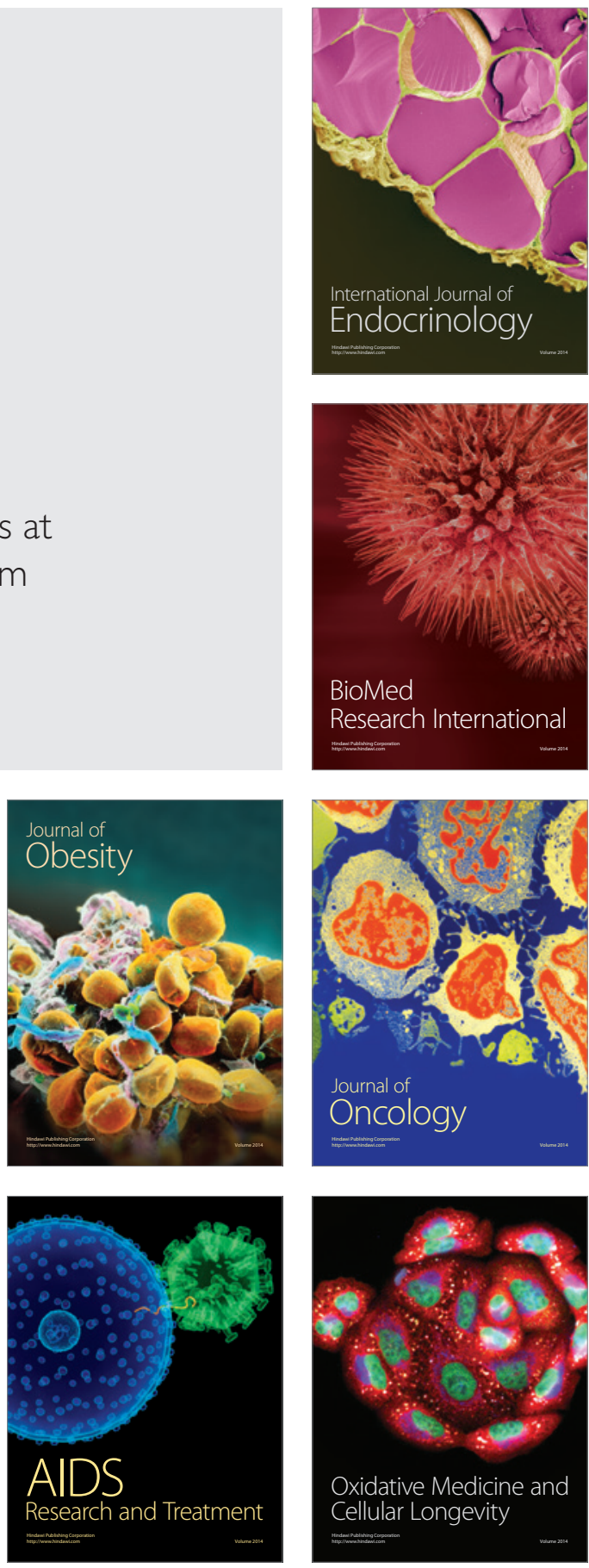